\title{
Investigating sustainable practices in the Malaysian office building developments
}

\begin{abstract}
Purpose - Economically, Malaysia has one of the fastest growing construction industries in the world; however, the necessary balance between socio-economic and ecological systems to avoid further environmental damage - has not yet been reached by the industry. This paper aims to explore the extent of sustainable development practices (socially, environmentally and economically) in the Malaysian construction industry, focusing on the office building sector. Design/methodology/approach - Semi-structured in-depth interviews with 30 stakeholders from various backgrounds of the Malaysian construction industry are used to explore their challenges and motivations for pursuing sustainable outcomes. Findings - The study finds that economic issues are the first priorities among stakeholders in any decisionmakings for building projects and cost becomes one of the major reasons for the slow progress in implementing sustainable practices in building projects. Socially, there is still a wide gap of knowledge and awareness on sustainability issues among stakeholders, explaining the lack of commitment in achieving sustainability. Research limitations/implications - The sample size is only adequate to enable internal generalisation; hence, further research is required to test the generalisability of the findings in this research. Practical implications - This paper informs the government and regulatory stakeholders, research and education sector, private sector, and clients of the building industry, where the authors currently are and the gaps that the authors have to bridge in order to make sustainability more socially acceptable and integral in the local construction industry. Originality/value - There have been very limited studies on exploring the views from various groups of stakeholders regarding all the three components of sustainable development in the Malaysian construction industry.
\end{abstract}

Keyword: Qualitative research; Malaysia; Office buildings; Building stakeholders; Design; Construction; Sustainability; Green buildings 